\title{
Características ecológicas e implicações para a conservação da Reserva Florestal do Morro Grande
}

\author{
Jean Paul Metzger', Luciana F. Alves ${ }^{2}$, Renata Pardini ${ }^{3}$, Marianna Dixo ${ }^{1}$, André do Amaral Nogueira ${ }^{3}$, Mônica de \\ Faria Franco Negrão ${ }^{4}$, Alexandre Camargo Martensen ${ }^{1} \&$ Eduardo Luís Martins Catharino ${ }^{2}$
}

Biota Neotropica v6 (n2)-http://www.biotaneotropica.org.br/v6n2/pt/abstract?article+bn01006022006

\author{
Recebido em 22/9/2005 \\ Versão reformulada recebida em 28/9/2005 \\ Publicado em 01/05/2006
}
${ }^{1}$ Departamento de Ecologia, Instituto de Biociências, Universidade de São Paulo, Rua do Matão, 321, travessa 14, 05509-900 São Paulo, SP (autor para correspondência: jpm@ib.usp.br)
${ }^{2}$ Instituto de Botânica, Caixa Postal 4005, 01061-970 São Paulo, SP
${ }^{3}$ Departamento de Zoologia, Instituto de Biociências, Universidade de São Paulo, Rua do Matão, 321, travessa 14, 05508-900 São Paulo, SP
${ }^{4}$ Departamento do Patrimônio Genético, Secretaria de Biodiversidade e Florestas, Ministério do Meio Ambiente, SCEN trecho 2 Ed. Sede do Ibama, Bloco G, 70818-900 Brasília, DF

\begin{abstract}
Metzger, J.P.; Alves, L.F.; Pardini, R.; Dixo, M.; Nogueira, A.A.; Negrão, M.F.F.; Martensen, A.C. \& Catharino E.L.M. Ecological characteristics of the Morro Grande Forest Reserve and conservation implications. Biota Neotrop. May/ Aug 2006 vol. 6 no. 2, http://www.biotaneotropica.org.br/v6n2/pt/abstract?article+bn01006022006. ISSN 1676-0603

In the last five years, the Morro Grande Forest Reserve (MGFR) has been systematically surveyed for different taxonomic groups. More than 13.000 individuals from 673 species of trees, nonvolant small mammals, birds, reptiles, anurans and orb-weaver spiders were sampled. The comparative analysis of the results reveals consistent biodiversity patterns which concern four central issues: i) the MGFR is situated in an ecotone location with the influence from the ombrophilous and mesophilous forests and also from the interior savanna region; ii) all taxonomic groups presented significant differences in species composition and/or richness when medium to old secondary forests (80 to 90 years of regeneration) were compared with old-growth forests (or "mature” forests), where only selective logging were observed; this should contribute to a high gamma diversity, given that the MGFR is a complex mosaic of vegetation in different successional stages; iii) partly due to the two first factors, the MGFR presents a consistent pattern of high species diversity when compared with other areas from the Atlantic Forest region; iv) due to its location in a high human density matrix, the MGFR is being submitted to strong disturbances, mostly related with hunting, vegetation exploitation, and alien species invasion. The conservation of this unique biota will depend on the establishment of a management plan that can take advantage of the proximity from the city of São Paulo, specially for projects of education, tourism and scientific research, and that could control the problems of exotic species, hunting, vegetation exploitation and inappropriate use of the MGFR surrounding.
\end{abstract}

Key words: Morro Grande Forest Reserve, Atlantic Forest, biodiversity, conservation, Atlantic Plateau 


\section{Resumo}

Metzger, J.P.; Alves, L.F.; Pardini, R.; Dixo, M.; Nogueira, A.A.; Negrão, M.F.F.; Martensen, A.C. \& Catharino E.L.M. Características ecológicas e implicações para a conservação da Reserva Florestal do Morro Grande. Biota Neotrop. May/Aug 2006 vol. 6 no. 2, http://www.biotaneotropica.org.br/v6n2/pt/abstract?article+bn01006022006. ISSN 1676-0603

Os levantamentos biológicos realizados nos últimos cinco anos na Reserva Florestal do Morro Grande (RFMG) permitiram inventariar mais de 13.000 indivíduos pertencentes a 673 espécies de árvores, mamíferos não-voadores, aves, répteis, anuros e aranhas orbitelas. A comparação dos dados obtidos revela padrões biológicos consistentes que levam a quatro conclusões principais: i) a RFMG se situa numa condição de transição, recebendo influências das florestas ombrófilas densas e mistas, das estacionais e até do cerrado; ii) todos os grupos taxonômicos estudados apresentam diferenças significativas na riqueza e/ou na composição de espécies quando comparadas as florestas em estádios sucessionais intermediários/avançados de sucessão (80-90 anos após corte raso) e a floresta madura, mais antiga (onde houve apenas corte seletivo), o que deve contribuir para um aumento da diversidade gama da RFMG, uma vez que esta é um complexo mosaico de vegetação em diferentes estádios sucessionais; iii) dado, em parte, aos dois fatores anteriores, a RFMG apresenta um padrão, consistente para diferentes grupos taxonômicos, de elevada riqueza de espécies quando comparada com outras áreas de Floresta Atlântica; iv) por sua localização numa matriz de alta densidade populacional humana, a RFMG vem sofrendo fortes perturbações, em particular devido à caça, extrativismo vegetal predatório e entrada de espécies exóticas e invasoras. A conservação da singular biota da RFMG dependerá do estabelecimento de um plano de manejo que consiga tirar vantagens da proximidade à cidade de São Paulo, em termos de pesquisa científica e projetos educacionais/turísticos, e estabeleça o controle das espécies exóticas, da caça, do extrativismo vegetal e da ocupação inadequada do seu entorno imediato.

Palavras-chave: Reserva Florestal do Morro Grande, Floresta Atlântica, diversidade biológica, conservação, Planalto Atlântico

http://www.biotaneotropica.org.br 


\section{Introdução}

A região sul do Planalto Atlântico paulistano foi apontada recentemente como uma área de Floresta Atlântica de provável importância biológica, mas onde o conhecimento científico era insuficiente para sua priorização em termos de conservação da biodiversidade (MMA 2000). Trata-se, efetivamente, de uma região de transição entre florestas ombrófilas e estacionais, e que, entretanto, foi pouco estudada até recentemente.

Neste contexto, a Reserva Florestal do Morro Grande (RFMG), em Cotia (SP), com seus 10.870 ha, representa uma das maiores extensões florestais deste Planalto. Desde há muito tempo, a RFMG já era reconhecida por seu valor para a conservação, em particular por seus recursos hídricos, tendo sido desapropriada no início do século XX, declarada Reserva Florestal em 1979, tombada pela Secretaria da Cultura do Governo do Estado de São Paulo em 1981, e incorporada à Reserva da Biosfera do Cinturão Verde da Cidade de São Paulo em 1994. No entanto, o conhecimento biológico das florestas da RFMG era, até o ano de 2000, incipiente, com apenas um levantamento mais detalhado realizado para a comunidade de abelhas (Aguilar 1998). Por sua localização e extensão, era premente a necessidade de um maior conhecimento desta Unidade de Conservação, justificando o intenso esforço de coleta feito na região nestes últimos cinco anos. Neste período, a RFMG e uma paisagem fragmentada adjacente, em Ibiúna (SP), foram objeto de estudos realizados no contexto de um projeto abrangente que objetivou elucidar os efeitos da fragmentação florestal sobre a flora e a fauna, considerando diferentes níveis de organização biológica (e.g., populações, comunidades), diversos taxa (plantas, vertebrados e invertebrados), processos ecológicos (dispersão de sementes, polinização, regeneração, entre outros), e escalas espaciais, da local à estrutura global da paisagem (Metzger 2000). Neste projeto, foram realizados levantamentos de árvores (Catharino et al. 2006), plântulas (Alves \& Metzger 2006), mamíferos (Negrão \& Valladares-Pádua 2006, Pardini \& Umetsu 2006), aves (Develey \& Martensen 2006), répteis e anuros (Dixo \& Verdade 2006), aranhas orbitelas (Nogueira et al. 2006) e borboletas (Uehara-Prado et al. 2004). Diante de sua importância, uma síntese dos resultados dos levantamentos obtidos exclusivamente na RFMG foi objeto desta série de artigos. O conjunto das informações obtidas na RFMG permite estabelecer quatro conclusões fundamentais a serem discutidas no presente artigo:

1. A RFMG apresenta características de ecótono, possivelmente por estar situada numa zona de transição climática e por ter tido, ao longo de sua história, influências de florestas ombrófilas densas e mistas, florestas mesófilas semi-decíduas e, em alguns casos, até do cerrado.

2. A composição e a riqueza de espécies variam em função da estrutura florestal, sendo que as assembléias são em geral mais ricas e incluem espécies mais exigentes nas porções de florestas mais maduras ou mais antigas (que não tiveram corte raso ou queima recente, apenas extração seletiva de madeira) em relação às florestas secundárias em estádio intermediário/avançado de sucessão, que sofreram corte raso há cerca de 80-90 anos atrás.

3. A RFMG possui, para diferentes grupos taxonômicos, uma riqueza de espécies elevada quando comparada com outras áreas de Floresta Atlântica, apesar de apresentar relativa homogeneidade ambiental (em particular, de altitude e relevo);

4. A RFMG vem sofrendo perturbações, muitas inerentes à sua localização numa matriz densamente habitada, que se refletem na baixa ocorrência de espécies de aves e mamíferos mais exigentes ou susceptíveis à caça, e na presença de algumas espécies exóticas que ameaçam a persistência das espécies nativas.

Além da discussão destes pontos, neste artigo apresentaremos, inicialmente, uma rápida síntese dos dados coletados, e discutiremos, ao final, as possíveis implicações dos dados coletados para a conservação da biodiversidade da RFMG.

\section{Levantamentos biológicos}

Das treze áreas inicialmente inventariadas na RFMG (Metzger et al. 2006), três foram abandonadas por questões de segurança (Ferrovia 1 e 2, Olaria). Das dez áreas restantes, seis foram inventariadas com mais detalhes, três em estádios sucessionais intermediários/avançados (A, B, C) e três em florestas predominantemente maduras ou mais antigas (Quilombo, Grilos e Torres, Tabela 1) (Metzger et al. 2006). O número de áreas estudadas por grupo variou de três a oito. Todas as amostragens, com exceção de plântulas, foram feitas tanto em áreas secundárias quanto em áreas de florestas maduras (Tabela 1).

Considerando apenas os levantamentos quantitativos obtidos com armadilhas, redes, pontos de escuta, parcelas ou quadrantes, foram amostrados 13.339 indivíduos pertencentes a 673 espécies, das quais grande parte é de árvores (260 espécies), aves (148) e aranhas (100, Tabela 2). Esta riqueza certamente poderia ser superior a 1000 espécies caso levantamentos mais extensos fossem empregados, em particular no caso de árvores, cuja estimativa de riqueza total é de cerca de 400-430 espécies (Catharino et al. 2006).

Deste conjunto de espécies, há muitas endêmicas da Floresta Atlântica, em particular dentre as árvores (150 a 200 espécies) e aves (56 espécies; Develey \& Martensen 2006). Em alguns casos, a taxa de endemismo supera 50\% das espécies observadas (pequenos mamíferos, árvores, por exemplo), podendo atingir 80\% do total (anuros e lagartos, Tabela 2). A RFMG apresenta também diversas espécies citadas nas listas oficiais como ameaçadas de extinção: treze 
aves (entre elas Hemitriccus orbitatus, Platyrinchus leucoryphus, Piculus aurulentus e Anabacerthia amaurotis), vinte árvores (entre elas a canela-sassafrás, Ocotea odorifera, a canela-imbuia, Ocotea porosa, a canelaamarela, Ocotea catharinensis, a araucária, Araucaria angustifolia e o xaxim-verdadeiro, Dicksonia sellowiana), um primata (Callithrix aurita), um carnívoro (Leopardus sp.) e um roedor (Rhagomys rufescens), três lagartos (Colobodactylus taunayi, Ecpleopus gaudichaudii e Enyalius perditus) e uma serpente (Echinanthera cianopleura), sem contar outras espécies cujo conhecimento é insuficiente para determinar o grau de ameaça. É notável, ainda, a presença de uma espécie nova de roedor, que aparentemente pertence a um gênero não descrito da tribo Oryzomyini, além de pelo menos duas (podendo ser até oito) espécies novas de aranhas, numa área a menos de 50 km do centro de São Paulo, uma das maiores metrópoles do mundo.

\section{A posição de ecótono da RFMG}

A localização geográfica da RFMG, no alto da Serra de Paranapiacaba, porém ainda próxima ao litoral e sem uma influência tão marcante da sazonalidade pluvial observada em regiões do interior, torna mais difícil classificar as suas florestas dentro das divisões fitofisionômicas tradicionais. Esta controvérsia é particularmente viva entre os botânicos, pois alguns consideram as florestas desta região como sendo estacionais, enquanto outros as classificam como "Florestas Ombrófilas Densas”, ou então sugerem que se trata de uma floresta de transição por agregar espécies das florestas ombrófilas e estacionais (ver revisão em Catharino et al. 2006). Os levantamentos florísticos realizados na RFMG dão suporte ao caráter de transição destas florestas. Segundo Catharino et al. (2006), apesar do clima predominantemente úmido no planalto, as florestas da RFMG ainda estão sujeitas à sazonalidade climática, podendo manter espécies associadas às florestas tropicais de climas mais quentes e sazonais do interior, tais como Croton floribundus, Machaerium stipitatum, Machaerium vestitum, Myrocarpus frondosus, Lafoensia pacari. Ademais, por apresentar também um clima montano, relativamente frio para sua latitude, as florestas da RFMG possuem ainda espécies típicas de florestas mistas, algumas em baixa densidade e freqüência, como Araucaria angustifolia, Podocarpus lambertii, Drimys brasiliensis, outras em densidades maiores, como a erva-mate (Ilex paraguariensis). Porém, sua composição florística é predominantemente formada por espécies das florestas ombrófilas densas, o que leva Catharino et al. (2006) a concluírem que, apesar de sua heterogeneidade, há uma relação mais íntima com as florestas da encosta ou Floresta Ombrófila Densa. As características de ecótono podem ser tanto determinadas por localização transicional atual, em termos de clima e solos, como também por paleoclimas passados que teriam propiciado o aporte de diferentes floras (ver discussão adiante).
Esta característica de transição observada para a flora também se repete para a avifauna. A RFMG apresenta certa influência das florestas mais secas do interior, mas de modo geral sua avifauna é muito mais semelhante às áreas de florestas úmidas situadas na Serra do Mar (Develey \& Martensen 2006). Por outro lado, em pequenos mamíferos e anuros, ressalta-se a nítida diferença na composição de espécies entre o Planalto (Dixo \& Verdade 2006, Pardini \& Umetsu 2006) e a Planície (a Estação Ecológica da Juréia, em particular). O número e distribuição dos levantamentos com as aranhas orbitelas ainda são insuficientes para concluir sobre padrões geográficos, porém foi atestada uma maior similaridade da RFMG com áreas mais próximas no Planalto paulistano (Serra da Cantareira) do que com áreas mais distantes (Juréia, Linhares, Nogueira et al. 2006). Este conjunto de resultados, apesar de não ser conclusivo pelo reduzido número de áreas comparadas, parece sugerir que há uma composição específica da fauna distinta nas regiões de Planalto, com elementos das florestas mais secas do interior, e em alguns caso com predominância de espécies das Florestas Ombrófilas Densas.

\section{Importância da estrutura e heterogeneidade das formações florestais}

Em todos os grupos para os quais foram feitos levantamentos em florestas predominantemente "maduras" (i.e., mais antigas), que sofreram apenas extração seletiva de madeira, e em florestas em estádios sucessionais intermediários/avançados (florestas que sofreram corte raso há 80-90 anos atrás), foram observadas diferenças na composição e/ou na riqueza de espécies. Para árvores, pequenos mamíferos, lagartos e anuros, as áreas maduras da RFMG são mais ricas em espécies do que as áreas secundárias (Tabela 3). Apenas para as aranhas orbitelas o padrão de riqueza é invertido, sendo as áreas secundárias ligeiramente mais ricas do que as de florestas maduras (Tabela 3). No caso de aves, considerando apenas as áreas na RFMG, essa comparação não foi possível, pois apenas uma área de floresta madura foi amostrada. Por outro lado, considerando levantamentos feitos com o mesmo método, esforço e investigador (Pedro Develey) nas florestas maduras do Parque Estadual de Jurupará, a apenas 30-40 km da RFMG, as riquezas locais (diversidades alfa) variaram de 75 a 87 espécies, bem acima de 55 a 70 espécies observadas pontualmente na RFMG (Tabela 3). Além de serem geralmente mais ricas em espécies para a maioria dos grupos taxonômicos, as áreas de floresta madura apresentam também uma maior freqüência de espécies estritamente florestais (características tardias, no caso de árvores, ou espécies de interior de floresta, mais susceptíveis à perturbação no caso da fauna).

Estas diferenças de riqueza e composição podem ser explicadas por diferentes fatores. Levey (1988) sugere que a maior variação sazonal na produção de frutos em florestas secundárias, comparativamente às florestas maduras, 
poderia provocar maior escassez de alimentos na época seca, o que por sua vez pode impedir algumas populações mais susceptíveis, em particular aquelas formadas por poucos indivíduos, de se manter localmente. A distribuição diferencial de espécies de Myrtaceae e Lauraceae, que fornecem recursos importantes para a fauna frugívora, sugere ainda que esta fauna depende, para sua manutenção, de um constante deslocamento pela RFMG (Catharino et al. 2006). Outro fator capaz de explicar a menor riqueza de aves nas áreas de florestas secundárias da RFMG, principalmente comparadas às florestas do Parque Estadual do Jurupará, é a menor abundância de sítios de nidificação para psitacídeos e ranfastídeos, que necessitam de uma floresta com árvores de grande porte. Mudanças na biomassa e umidade da serrapilheira observadas nas florestas secundárias em relação às maduras podem também restringir espécies associadas ao folhiço, como no caso de duas espécies de roedor (Thaptomys nigrita e Blarinomys breviceps) e uma de marsupial (Monodelphis scalops). Ademais, o maior porte e complexidade da estrutura vegetal em florestas maduras facilitariam o deslocamento de espécies arborícolas, como os roedores Rhipidomys mastacalis e Juliomys pictipes, ou propiciariam maiores oportunidades para a disposição das teias das aranhas orbitelas, favorecendo algumas espécies e justificando parte da variação na composição específica deste grupo (Nogueira et al. 2006). Finalmente, outros fatores, como diferenças no microclima, na qualidade, abundância e diversidade de micro-habitats podem estar na base das modificações na estrutura das comunidades de aves, pequenos mamíferos, anuros e aranhas, porém o estabelecimento de relações causais necessitaria de estudos experimentais mais específicos.

Em conseqüência das variações nas composições das comunidades em áreas em diferentes estádios de desenvolvimento sucessional, é possível observar, para a comunidade arbórea, que as áreas mais heterogêneas, compostas por um mosaico de florestas em diferentes estádios sucessionais, tendem a ser as áreas mais ricas em espécies (Catharino et al. 2006). Áreas como Torres e Grilos, que apresentam maior heterogeneidade, têm uma combinação de espécies consideradas tardias com outras de estádios mais iniciais de sucessão, enquanto áreas exclusivamente mais maduras (como Quilombo) ou mais intermediárias têm menos espécies, seja por terem menos espécies pioneiras/iniciais, seja pela redução do número de espécies tardias. Em relação à fauna, este padrão não foi observado, havendo sistematicamente maior riqueza nas áreas mais maduras (Quilombo, Capelinha) em relação às áreas com vegetação mais heterogênea (Torres e Grilos). Mas não há dúvidas que devido à variação na composição específica da fauna em função do tipo de vegetação, numa escala mais ampla (regional), a diversidade gama da RFMG deve ser maior em função da heterogeneidade do mosaico florestal.

\section{Riqueza de espécies particularmente elevada}

Quando comparada com outras áreas de Floresta Atlântica de extensão semelhante, a RFMG apresenta um padrão de elevada riqueza de espécies para diferentes grupos taxonômicos, em particular árvores, pequenos mamíferos não-voadores, aranhas orbitelas e anuros de serrapilheira. A riqueza arbórea da RFMG é estimada em cerca de 400-430 espécies (Catharino et al. 2006), o que é bem superior às cerca de 300-350 espécies observadas em florestas similares dos planaltos paulistanos inventariadas de forma mais exaustiva, como o Parque Estadual das Fontes do Ipiranga (Gomes 1992, 1998). Riqueza e abundância altas também foram observadas para pequenos mamíferos. A riqueza local (diversidade alfa) na RFMG foi de 11 a 18 espécies (Pardini \& Umetsu 2006), enquanto foram observadas cerca de 11 espécies por sítio em outras áreas de Floresta Atlântica (Vieira 1999). No caso de aranhas orbitelas, o estudo de Nogueira et al. (2006) obteve a maior riqueza já registrada para o grupo em áreas de Floresta Atlântica (100 espécies), bem superior às 66 espécies observadas no Parque Estadual da Cantareira com o mesmo método e esforço similar aos empregados na RFMG (Pinto-da-Rocha, dados não publicados). Finalmente, para os anuros associados à serrapilheira, a RFMG foi considerada uma das áreas mais ricas (18 espécies), perdendo em número de espécies somente para Boracéia e Paranapiacaba, ambas com 25 espécies registradas ao longo de aproximadamente 70 anos (Dixo \& Verdade 2006).

Diferentes hipóteses são propostas para explicar estes valores de riqueza. Algumas destas razões seriam apenas circunstanciais. A riqueza elevada de aranhas orbitelas e de pequenos mamíferos poderia estar relacionada a um esforço de coleta particularmente intensivo, ou então ao emprego de técnicas mais eficientes, como a coleta noturna em dois diferentes períodos da estação chuvosa, o que deve favorecer a captura de maior número de indivíduos de aranhas orbitelas; ou então o uso de grandes baldes, de 60 litros, mais eficientes que armadilhas Sherman na captura de pequenos mamíferos não-voadores (Umetsu et al. no prelo). No entanto, pelo menos no caso de pequenos mamíferos, com os mesmos métodos e mesmo esforço de captura na região da Reserva Biológica do Una (Sul da Bahia), foi encontrada menor riqueza de espécies (Pardini 2004).

Outras possíveis razões para a maior diversidade da RFMG podem estar ligadas a questões biogeográficas, uma vez que a Floresta Atlântica do Sul do país é sistematicamente mais rica em espécies de pequenos mamíferos que a encontrada ao Norte do Rio de Janeiro (Moura 2003), ou ainda que florestas de altitudes intermediárias (500 a $1500 \mathrm{~m}$ ) tendem a ser mais ricas que as demais (Pardini \& Umetsu 2006). Catharino et al. (2006) lembram ainda que a região serrana de Caucaia foi supostamente um refúgio “alto-montano” que teria permitido a conservação da flora arbórea do sul-sudeste do Brasil em 
épocas de clima mais seco durante o Pleistoceno (Ab’Saber 1992). A diversidade da flora amostrada na região, combinando elementos de florestas úmidas da encosta Atlântica com outras espécies de climas mais frios do Sul e estacionais do interior de São Paulo, parece confirmar esta hipótese (Catharino et al. 2006). Finalmente, a heterogeneidade do mosaico florestal, combinando comunidades distintas de florestas secundárias e maduras, parece favorecer a ocorrência de uma maior diversidade gama, no conjunto da RFMG.

Este padrão de alta riqueza não foi observado para todos os grupos. Em particular, a RFMG apresenta uma riqueza relativamente baixa no caso de mamíferos de maior porte (18 espécies versus 36 em Unidades de Conservação de cerca de 20.000 ha do Espírito Santo) e de aves florestais (148 espécies na RFMG versus 160-200 em outras áreas como na Estação Ecológica Juréia-Itatins e em Salesópolis). Estes baixos valores podem estar associados ao fato do gradiente altitudinal dentro da RFMG, de apenas 260 m, ser muito menor que o de outras Unidades de Conservação de Floresta Atlântica, o que certamente reduz a diversidade beta. Ademais, em função deste relevo mais plano e homogêneo, a RFMG não apresenta rios muito encaixados, onde em geral são observadas elevadas riquezas florísticas (Mantovani et al. 1989), que poderia também suportar uma avifauna mais diversificada, especialmente de frugívoros de dossel (Develey \& Martensen 2006). Ademais, grande parte da RFMG é formada por florestas em estádios intermediários de sucessão, que no caso de aves, são menos ricas que as florestas maduras. De fato, ao compararmos a RFMG com o Parque Estadual de Jurupará, situado em condições ambientais semelhantes, porém onde há maiores extensões de florestas maduras, nota-se uma grande diferença no número de espécies florestais observadas (Develey 2004). Possivelmente cerca de 35 a 40 espécies estão ausentes na RFMG em função da falta de maiores extensões de florestas maduras (Develey \& Metzger no prelo). Trata-se, em geral, de espécies de frugívoros de dossel (Selenidera maculirostris ou Ramphastos dicolorus) ou de pequenos insetívoros (como Formicarius colma e Piprites chloris), mas também de espécies cinegéticas. A caça é também uma das principais razões a que atribuímos a baixa riqueza de grandes mamíferos, mais propensos a serem alvo dos caçadores.

Desta forma, excluindo os grupos particularmente sensíveis à caça (aves e mamíferos de grande porte), a riqueza observada na RFMG é alta, o que pode estar relacionado à sua condição passada de refúgio alto-montano, ou à confluência de diferentes floras e faunas, indicando uma possível situação de ecótono, ou então a características particulares, como alta heterogeneidade do mosaico florestal, que favorece valores elevados de diversidade beta e gama.

\section{Perturbações recentes na RFMG}

As características predominantemente secundárias das florestas da RFMG denotam sua ocupação passada. Provavelmente, no início do século XX, cerca de 75\% da RFMG não apresentava cobertura florestal. As florestas atuais são em grande parte resultado do processo de regeneração ocorrido nos últimos 80-90 anos e de recolonizações da fauna, provavelmente facilitadas pela proximidade da RFMG com as florestas da Serra de Paranapiacaba. Além destas perturbações passadas, a RFMG ainda apresenta sinais claros de impactos atuais, em particular devido à caça, extrativismo vegetal e introdução de espécies exóticas.

Os efeitos da caça aparecem na composição de espécies de aves e de mamíferos de maior porte. A forte pressão de caça na RFMG pode explicar a ausência de algumas espécies cinegéticas, como o macuco (Tinamus solitarius) e a jacutinga (Pipile jacutinga), que foram totalmente extintas da RFMG, e mesmo o nhambu-guaçu (Crypturellus obsoletus) e o jacu (Penelope obscura), que são muito raros e devem ter sido muito caçados (Develey \& Martensen 2006). No caso dos mamíferos de maior porte, a comunidade é composta essencialmente por espécies de tamanho reduzido e generalistas, pouco sensíveis à presença humana ou à caça. As maiores espécies presentes na RFMG, o veado (Mazama sp.), a capivara (Hydrochaeris hydrochaeris) e o bugio (Alouatta guariba), possuem dieta frugívora/herbívora, herbívora e herbívora/folívora. Os grandes carnívoros, como a suçuarana (Puma concolor), e as espécies cinegéticas, como a queixada (Tayassu pecari), o cateto (Pecari tajacu), a paca (Agouti paca) e a cutia (Dasyprocta sp.), parecem extintas ou são muito raras nas florestas da RFMG, o que pode caracterizar, para alguns autores, florestas “vazias” (“empty forest”, sensu Redford 1992). A ausência destas espécies pode ter uma série de conseqüências sobre o funcionamento do sistema. Em particular, a RFMG pode ter perdido espécies essenciais para dispersão de sementes de grande porte (Silva \& Tabarelli 2000), ou ainda pode ter perdido os predadores que controlavam as populações de animais de médio porte, como o gambá (Didelphis aurita). A elevada abundância desta espécie na RFMG (Negrão \& Valladares-Pádua 2006), por sua vez, pode excluir pequenos roedores e marsupiais por competição ou predação (Fonseca \& Robinson 1990), numa contínua regulação do topo em direção à base da cadeia (“top-down”).

Além da caça, a RFMG apresenta também espécies exóticas que podem contribuir para a extinção de espécies nativas. Este parece ser o caso do mico-estrela Callithrix penicillata), espécie característica do Cerrado, mas que vem invadindo algumas áreas de Floresta Atlântica (Hirsch 1995, Bueno 2004). A co-ocorrência deCallithrix penicillata com C. aurita, espécie típica de Floresta Atlântica e ameaçada de extinção, acentua a sua vulnerabilidade, não apenas pela 
competição por recursos, mas também pelo risco de hibridização das duas espécies (Negrão \& Valladares 2006). Outra espécie que vem se expandindo devido à ausência de predadores é o lebre européia (Lepus capensis), espécie exótica, de origem européia, inicialmente importada por criadores da região de Paraguaçu Paulista (Negrão \& Valladares 2006). Estudos pioneiros com esta espécie indicam a redução populacional da espécie nativa, o tapiti (Sylvilagus brasiliensis), concomitantemente ao aumento populacional da lebre, sugerindo o deslocamento do tapiti (Grigera e Rapoport 1983, Daniel Munari comunicação pessoal). Entre os anuros, registrou-se a presença da rã touro (Rana catesbeiana), espécie de uso comercial. Apesar de ainda rara na RFMG, potencialmente a rã touro pode impactar as espécies nativas uma vez que ela compete por recursos e pode predar algumas destas espécies (Guix 1990). Provavelmente um dos principais problemas com espécies exóticas na RFMG está relacionado com a grande freqüência de animais domésticos, principalmente cachorros e gatos, vindo de habitações vizinhas ou entrando junto com caçadores. Estes animais são eficientes predadores de ninhos, roedores, marsupiais, além de poderem espalhar diversas doenças para as espécies nativas (Liberg 1984, Butler et al. 2004, Campos 2004).

Por outro lado, a invasão de espécies parece incipiente no caso de pequenos mamíferos, aves e de espécies arbóreas. Nenhuma espécie exótica e invasora foi observada entre as plântulas (Alves \& Metzger 2006), e apenas uma exótica foi amostrada entre as árvores adultas, a nespeira (Eryobotrya japonica, Rosaceae), o que pode indicar uma certa resistência da vegetação nativa à proliferação destas espécies (Bernacci et al. submetido). Ressalta-se o risco de invasão de algumas espécies zoocóricas a partir das áreas de uso da SABESP, notadamente do Pittosporum undulatum (européia) e da palmeira-seafórtia (Archontophenix cunninghamiana, australiana), que ocorrem em alta densidade no subosque de áreas florestais adjacentes à Estação de Tratamento e Reservatório Pedro Beicht. Com a dispersão por aves frugívoras, estas espécies tendem, em pouco tempo, a ocupar o nicho de espécies nativas de subosque (Psychotria spp) e de dossel (Euterpe edulis) (E. Catharino observações não publicadas).

Outra indicação clara de perturbação é a exploração da Euterpe edulis (palmito-juçara), praticamente extinta na RFMG, salvo em pequenas manchas de florestas maduras, em geral de acesso mais difícil. Este extrativismo predatório, além de impedir a reprodução da espécie, pode ter inúmeras conseqüências, pois o fruto do palmito é um recurso abundante utilizado por um grande número de espécies frugívoras da Floresta Atlântica, podendo ser, em algumas épocas do ano, essencial para a sobrevivência de algumas espécies (Galetti \& Aleixo 1998).
Enfim, são claros os impactos recentes sofridos pela RFMG, muitos deles relacionados à sua localização próxima à cidade de São Paulo e a outros adensamentos urbanos, como os de Cotia, Vargem Grande e Embu (Metzger et al. 2006). Esta alta densidade populacional humana no entorno da RFMG implica num extenso "efeito de borda" (sensu Laurance 2000), com aumento dos riscos de entrada clandestina da população, assim como de invasão de espécies exóticas, em particular de animais domésticos (gatos e cachorros). Ademais, nas bordas com áreas agrícolas, a oeste da RFMG, há contaminação com produtos químicos utilizados como adubos, pesticidas e herbicidas, que podem ter impactos significativos sobre a fauna, porém ainda não estudados. Finalmente, ao longo da estrada de ferro que corta a RFMG ao sul, há a ocorrência freqüente de incêndios florestais, principalmente nas épocas mais secas. Esta situação torna particularmente urgente a definição de um plano de manejo e de estratégias de conservação para a RFMG.

\section{Implicações para a conservação}

Alguns dos resultados produzidos por estes estudos são bastante animadores. Em particular, a alta densidade e riqueza de espécies de plântulas, e a ausência de espécies exóticas ou invasoras neste estrato da floresta indica que a regeneração florestal está ocorrendo espontaneamente, até mesmo nas áreas secundárias da RFMG (Alves \& Metzger 2006). A alta conectividade das florestas da RFMG com aquelas da Serra de Paranapiacaba, formando praticamente um contínuo florestal abrangendo diversas unidades de conservação (os Parques Estaduais de Jurupará, Carlos Botelho, Intervales e Turístico do Alto Ribeira), certamente facilita a recolonização ou o efeito de resgate das populações presentes na RFMG. Portanto, a RFMG não necessitaria de ações de restauração mais custosas, como o reflorestamento ou o enriquecimento com espécies nativas, ou o repovoamento de espécies extintas de animais. Os próprios processos naturais de regeneração e recolonização poderiam suprir as eventuais perdas de espécies, não fossem os impactos mais intensos que a RFMG vem sofrendo.

De fato, a RFMG está inserida numa matriz extremamente agressiva, seja pela alta densidade populacional de seu entorno, seja pela presença de um cinturão agrícola com amplo uso de produtos químicos, resultando num largo "efeito de borda”. Os problemas relacionados à caça, extrativismo vegetal predatório e presença de espécies exóticas ou invasoras necessitam de manejo imediato, que deveria ser discutido e elaborado quando do estabelecimento do Plano de Manejo da Unidade de Conservação. Para a definição deste plano de ação é necessária uma ampla discussão dos problemas e usos desejados da RFMG, que deverá envolver diferentes setores da sociedade, incluindo pesquisadores com diferentes especialidades, a sociedade civil do entorno e a atual gestora 
da RFMG, a SABESP. Não nos cabe aqui antecipar este fórum de discussão e apresentar "soluções definitivas" aos problemas da RFMG, porém os dados que obtivemos permitem delinear algumas diretrizes de cunho biológico que poderão alimentar a discussão de um plano de manejo e gestão da Reserva.

- É necessário o imediato controle de espécies exóticas, em particular o mico-estrela (Callithrix penicillata), a lebre européia (Lepus capensis), a rã touro (Rana catesbeiana) e cães e gatos domésticos. Provavelmente, a ação mais adequada para a conservação das espécies nativas é a retirada completa das exóticas, ou quando não for possível, um rígido controle populacional. Da mesma forma, deve-se monitorar a proliferação de espécies exóticas da flora, evitando-se seu plantio dentro ou no entorno da unidade.

- Conforme exigência do Sistema Nacional de Unidades de Conservação da Natureza ${ }^{1}$, é necessário enquadrar a RFMG numa das categorias permanentes de Unidade de Conservação. A importância biológica evidenciada nos estudos aqui sintetizados indica a necessidade de se garantir a conservação e uma efetiva proteção da RFMG, incluindo maior fiscalização e controle de atividades ilegais (especialmente caça, extrativismo e incêndios propositais), zoneamento com definição de áreas intangíveis (em particular nas áreas de florestas maduras, ao sul da Reserva) e controle do uso da reserva (plano de visitação, proibição de entrada de animais domésticos, entre outros). Neste sentido, é necessário o enquadramento da Reserva em uma das categorias de unidade de proteção integral. As alternativas a serem discutidas incluem: i) Parque Estadual, que abre a possibilidade de desenvolvimento de atividades de turismo ecológico e de educação ambiental em ampla escala; ii) Reserva Biológica, que estaria voltada mais exclusivamente à proteção da biota e à pesquisa; iii) Estação Ecológica, que objetiva a geração de conhecimento científico;

- Devido à sua proximidade com a cidade de São Paulo, a RFMG apresenta um potencial turístico e educativo que poderia ser explorado mais intensamente, em particular se for decidida a sua inclusão na categoria de Parque Estadual.

- Ainda devido à proximidade com São Paulo e suas Universidades e centros de pesquisa, há também um grande potencial para estudos biológicos de longo prazo, como o monitoramento de populações nativas, estabelecimento de parcelas permanentes para estudo da vegetação, entre outros. A infra-estrutura já existente, incluindo uma casa para pesquisa que pode alojar de 15 a 20 pessoas, favorece estes estudos.

- A RFMG necessita o estabelecimento de uma real Zona de Amortecimento no seu entorno, que neste momento é inexistente. Caso contrário, os efeitos de borda, já extensos, tendem a se intensificar com a propagação de loteamentos de alta densidade populacional, principalmente a leste da RFMG, ou com o uso indiscriminado de adubos, pesticidas e herbicidas a oeste da RFMG.

\section{Conclusão}

O conjunto dos dados biológicos obtidos nestes últimos cinco anos reforça a importância da RFMG para a conservação da biota regional. Além de abrigar flora e fauna que englobam elementos de diferentes regiões (interior, serras/litoral, região sul), possivelmente por ter sido no passado um refúgio altomontano, a RFMG possui riqueza particularmente alta de espécies para diferentes taxa, incluindo diversas espécies endêmicas, ameaçadas e até espécies novas para a ciência, fato surpreendente para uma floresta tão próxima da cidade de São Paulo. Esta proximidade implica em fortes pressões de perturbação, mas também num potencial ainda pouco explorado para o estabelecimento de programas turísticos, educativos e científicos. É principalmente através da ciência e da educação que será possível contribuir para a conservação de singular biota da RFMG.

\section{Agradecimentos}

A todos que propiciaram estes estudos na RFMG, em particular ao José Roberto Nali, à Cristina Oka e aos funcionários da SABESP, que sempre nos deram o respaldo local para os trabalhos de campo; à FAPESP, pelo auxílio temático (BIOTA 99/05123-4) e numerosas bolsas de iniciação científica, mestrado, doutorado e pós-doutorado; ao Carlos Joly, por apoiar a idéia desta série especial de artigos na Biota Neotropica; ao Thomas Lewinsohn, por sua atuação como editor desta série especial e pela revisão crítica deste artigo; a todos os colegas assessores que auxiliaram na correção e no aprimoramento dos artigos apresentados nesta série especial.

\section{Referências}

AB'SÁBER, A.N. 1992. A Serra do Japi, sua origem geomorfológica e a teoria dos refúgios. In Ecologia e preservação de uma área florestal no Sudeste do Brasil (L.P. Morellato, org.). Editora da Unicamp/Fapesp, Campinas, p.12-23.

AGUILAR, J.B.V. 1998. A comunidade de abelhas (Hymenoptera: Apoidea) da Reserva Florestal de Morro Grande, Cotia, São Paulo. Tese de doutorado, Instituto de Biociências, Universidade de São Paulo.

ALVES, L.F. \& METZGER, J.P. 2006. A regeneração florestal em áreas de floresta secundária na Reserva Florestal do Morro Grande, Cotia, SP. Biota Neotrop. 6(2): http://www.biotaneotropica.org.br/v6n2/pt/ abstract?article+bn00606022006 (último acesso em 03/05/2006).

\footnotetext{
${ }^{1}$ Lei Federal $n^{\circ}$ 9.985, de 18 de Julho de 2000, e decreto $n^{\circ} 4.340$, de 22 de Agosto de 2002.
}

http://www.biotaneotropica.org.br 
BERNACCI, L.C., FRANCO, G.A.D.C., ARBOCZ, G., CATHARINO, E.L., DURIGAN, G. \& METZGER, J.P. Composição e riqueza arbórea na Reserva Florestal do Morro Grande e numa paisagem fragmentada adjacente (Planalto de Ibiúna, SP). Submetido.

BUENO, R.S. 2004. Distribuição potencial de Callithrix exóticos na mata Atlântica, Rio Claro, SP, Universidade Estadual Paulista. http://ns.rc.unesp.br/ib/ecologia/ fenologia/rafaelbueno.htm (último acesso em 02/05/2006).

BUTLER, J.R.A., DU TOIT, J.T. \& BINGHAM, J. 2004. Free ranging domestic dogs (Canis familiaris) as predators and prey in rural Zimbabwe: threats of competition and disease to large wild carnivores. Biol. Conserv. 115:369-378.

CAMPOS, C.B. 2004. Impacto de cães (Canis familiaris) e gatos (Felis catus) errantes sobre a fauna silvestre em ambiente peri-urbano. Dissertação de mestrado, ESALQUSP, Piracicaba.

CATHARINO, E.L., BERNACCI, L.C., FRANCO, G.A.D.C., DURIGAN, G. \& METZGER, J.P. 2006. Aspectos da composição e diversidade do componente arbóreo das florestas da Reserva Florestal do Morro Grande, Cotia, SP. Biota Neotrop. 6(2): http://www.biotaneotropica.org.br/v6n2/pt/ abstract?article+bn00306022006 (último acesso em 03/05/2006).

DEVELEY, P.F. 2004. Efeitos da fragmentação e do estado de conservação da floresta da diversidade de aves de Mata Atlântica. Tese de doutorado, Universidade de São Paulo, São Paulo.

DEVELEY, P.F. \& METZGER, J.P. (no prelo). Emerging threats to birds in Brazilian Atlantic Forest: the roles of forest loss and configuration in a severely fragmented ecosystem. In: Emerging threats to tropical forests. (C.A. Peres \& W.F. Laurance, eds.). University of Chicago Press, Chicago.

DEVELEY, P.F. \& MARTENSEN, A.C. 2006. As aves da Reserva Florestal do Morro Grande, Cotia (SP). Biota Neotrop. 6(2): http://www.biotaneotropica.org.br/ v6n2/pt/abstract?article+bn00906022006 (último acesso em 03/05/2006).

DIXO, M. \& VERDADE, V.K. 2006. Herpetofauna de serrapilheira da Reserva Florestal do Morro Grande, Cotia (SP). Biota Neotrop. 6(2): http:// www.biotaneotropica.org.br/v6n $2 / \mathrm{pt} /$ abstract?article+bn00706022006 (último acesso em 03/05/2006).

FONSECA, G.A.B. \& ROBINSON, J.G. 1990. Forest size and structure: competitive and predatory effects on small mammal communities. Biol. Conser. 53:265-294.

GALETTI, M. \& ALEIXO, A. 1998. Effects of palm heart harvesting on avian frugivores in the Atlantic rain forest of Brazil. J. Appl. Ecol. 35:286-293
GOMES, E.P.C. 1992. Fitossociologia do componente arbóreo de um trecho de mata em São Paulo, SP. Dissertação de mestrado. Instituto de Biociências, Universidade de São Paulo, SP.

GOMES, E.P.C. 1998. Dinâmica do componente arbóreo de um trecho de mata em São Paulo, SP. Tese de doutorado, Instituto de Biociências, Universidade de São Paulo, São Paulo.

GRIGERA, D.E. \& RAPOPORT, E.H. 1983. Status and distribution of the European Hare in South America. J. Mammal 64:163-166.

GUIX, J.C. 1990. Introdução e colonização de Rana catesbeiana Shaw, 1802 em um pequeno vale no município de Suzano (SP), Sudeste do Brasil. Grupo Estudos Ecol. Ser. Doc. 2:32-34.

HIRSCH, A. 1995. Censo de Alouatta fusca Geoffroy, 1812 (Platyrrhini, Atelidae) e qualidade do habitat em dois remanescentes de Mata Atlântica em Minas Gerais. Tese de mestrado, Universidade Federal de Minas Gerais, Belo Horizonte.

LAURANCE, W.F. 2000. Do edge effects occur over large spatial scales? Trends Ecol. Evol. 15:134-135.

LEVEY, D.J. 1988. Spatial and temporal variation in Costa Rican fruit and fruit-eating bird abundance. Ecol. Monogr. 58:251-269.

LIBERG, O. 1984. Food habits and prey impact by feral and house-based domestic cats in a rural area in southern Sweden. J. Mammal. 65:424-432.

MANTOVANI, W., RODRIGUES, R.R., ROSSI, L., ROMANIUC-NETO, S., CATHARINO, E.L.M. \& CORDEIRO, I. 1989. A vegetação na Serra do Mar em Salesópolis, SP. In Anais do II Simpósio de ecossistemas da costa Sul e Sudeste brasileira: estrutura, funcionamento e manejo. São Paulo, vol. 2, p.348-384.

METZGER, J.P. (coordenador). 2000. Conservação da Biodiversidade em Paisagens Fragmentadas no Planalto Atlântico de São Paulo. Projeto Temático BIOTA/ FAPESP (Processo nº 99/05123-4), São Paulo, SP.

METZGER, J.P., ALVES, L.F., GOULART, G., TEIXEIRA, A.M.G., SIMÕES, S.J.C. \& CATHARINO, E.L.M. 2006. Uma área de relevante interesse biológico, porém pouco conhecida: a Reserva Florestal do Morro Grande. Biota Neotrop. 6(2): http://www.biotaneotropica.org.br/v6n2/ pt/abstract?article+bn00406022006 (último acesso em 03/05/2006).

MINISTÉRIO DO MEIO AMBIENTE (MMA), 2000. Avaliação e ações prioritárias para a conservação da biodiversidade da Mata Atlântica e campos sulinos. Conservation International do Brasil, Fundação SOS Mata Atlântica, Fundação Biodiversitas, Instituto de Pesquisas Ecológicas, Secretaria do Meio Ambiente do Estado de São Paulo SEMAD / Instituto Estadual de Florestas-MG. Brasília. 
MOURA, R.T. de. 2003. Distribuição e ocorrência de mamíferos na Mata Atlântica do Sul da Bahia. In: Corredor de Biodiversidade da Mata Atlântica do Sul da Bahia. (P.I. Prado, E.C. Landau, R.T. Moura, L.P.S. Pinto, G.A.B. Fonseca, K.N. Alger, coords.). Publicação em CD-ROM, IESB / CI / CABS / UFMG / UNICAMP, Ilhéus.

NEGRÃO, M.F.F. \& VALLADARES-PÁDUA, C. 2006. Registros de mamíferos de maior porte na Reserva Florestal do Morro Grande, São Paulo. Biota Neotrop. 6(2): http://www.biotaneotropica.org.br/v6n2/pt/ abstract?article+bn00806022006 (último acesso em 03/05/2006).

NOGUEIRA, A.A., PINTO DA ROCHA, R. \& BRESCOVIT, A.D. 2006. Comunidade de aranhas orbitelas (Arachnida - Araneae) da região da Reserva Florestal do Morro Grande, Cotia, São Paulo, Brasil. Biota Neotrop. 6(2): http://www.biotaneotropica.org.br/v6n2/pt/ abstract?article+bn00206022006 (último acesso em 03/ 05/2006).

PARDINI, R. 2004. Effects of forest fragmentation on small mammals in an Atlantic Forest landscape. Biodiv. Conserv. 13:2567-2586.

PARDINI, R. \& UMETSU, F. 2006. Pequenos mamíferos nãovoadores da Reserva Florestal do Morro Grande distribuição das espécies e da diversidade em uma área de Mata Atlântica. Biota Neotrop. 6(2): http:// www.biotaneotropica.org.br/v6n2/pt/ abstract?article+bn01006022006 (último acesso em 03/ 05/2006).

PARDINI, R., SOUZA, S.M. de, BRAGA-NETTO, R. \& METZGER, J.P. 2005. The role of forest structure, fragment size and corridors in maintaining small mammal abundance and diversity in a tropical forest landscape. Biol. Cons. 124:253-266.

REDFORD, K.H. 1992. The empty forest. Bioscience 42:412-422.

SILVA, J.M.C. \& TABARELLI, M. 2000. Tree species impoverishment and the future flora of the Atlantic forest of northeast Brazil. Nature 404:72-74.

UEHARA-PRADO, M., FREITAS, A.V.L., FRANCINI, R.B. \& BROWN JR, K.S. 2004. Guia das Borboletas Frugívoras da Reserva Estadual do Morro Grande e região de Caucaia do Alto, Cotia (São Paulo). Biota Neotrop. 4:1-25. http://www.biotaneotropica.org.br/ v4n1/ (último acesso em 02/05/2006).

UMETSU, F., NAXARA, L. \& PARDINI, R. Evaluating the efficiency of pitfall traps for sampling small mammals in the Neotropics. J. Mammal 87, no prelo.

VIEIRA, E.M. 1999. Estudo comparativo de comunidades de pequenos mamíferos em duas áreas de Mata Atlântica situadas a diferentes altitudes no sudeste do Brasil. Tese de doutorado, Universidade Estadual de Campinas, Campinas.
Título: Ecological characteristics of the Morro Grande Forest Reserve and conservation implications

Autores: Metzger, J.P.; Alves, L.F.; Pardini, R.; Dixo, M.; Nogueira, A.A.; Negrão, M.F.F.; Martensen, A.C. and Catharino E.L.M.

Biota Neotropica, Vol. 6 ( número 2): 2006 http://www.biotaneotropica.org.br/v6n2/pt/ abstract?article+bn01006022006

Recebido em 22/9/2005 - Versão reformulada recebida em 28/9/2005 -Publicado em 01/05/2006

ISSN 1676-0603 


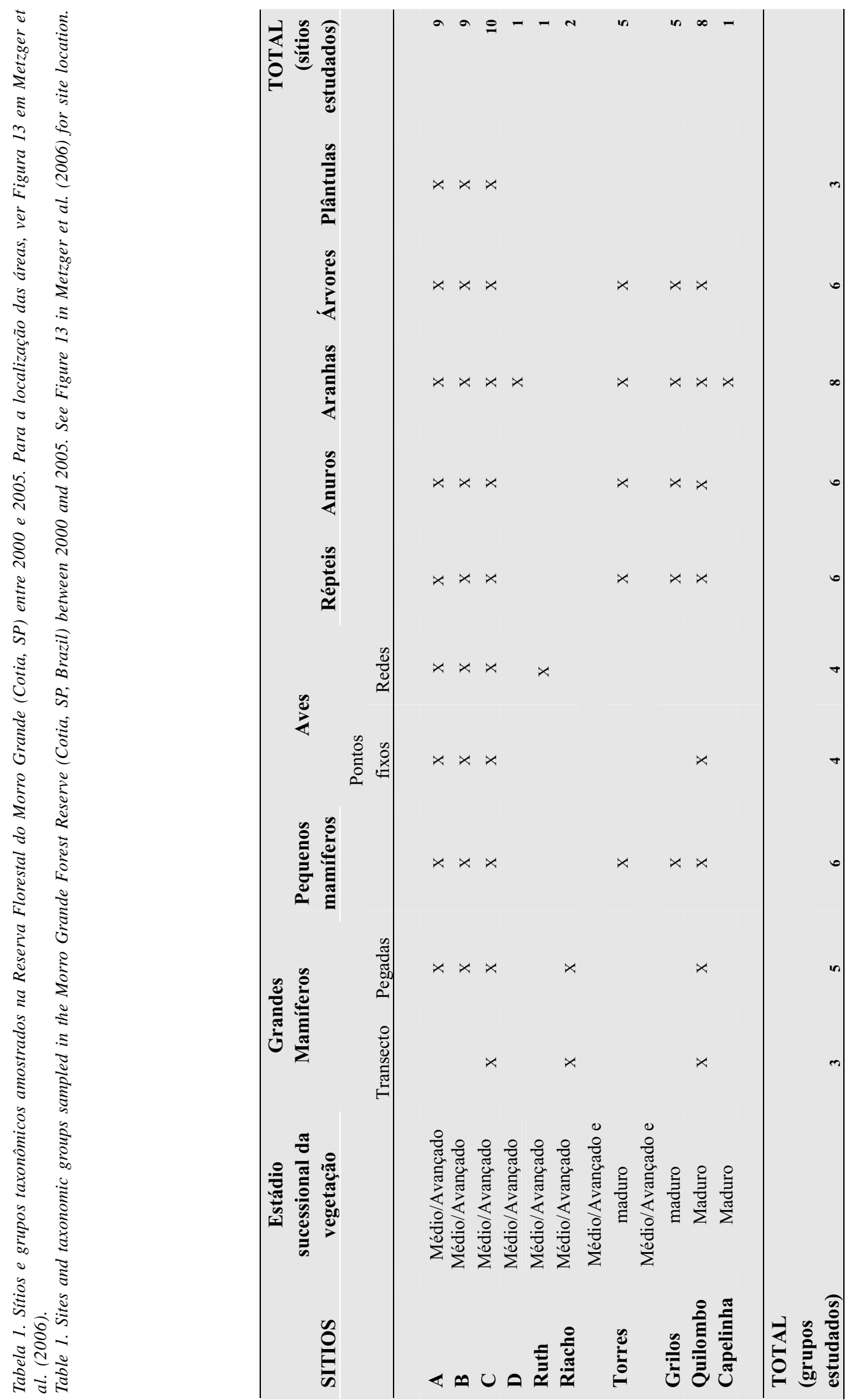




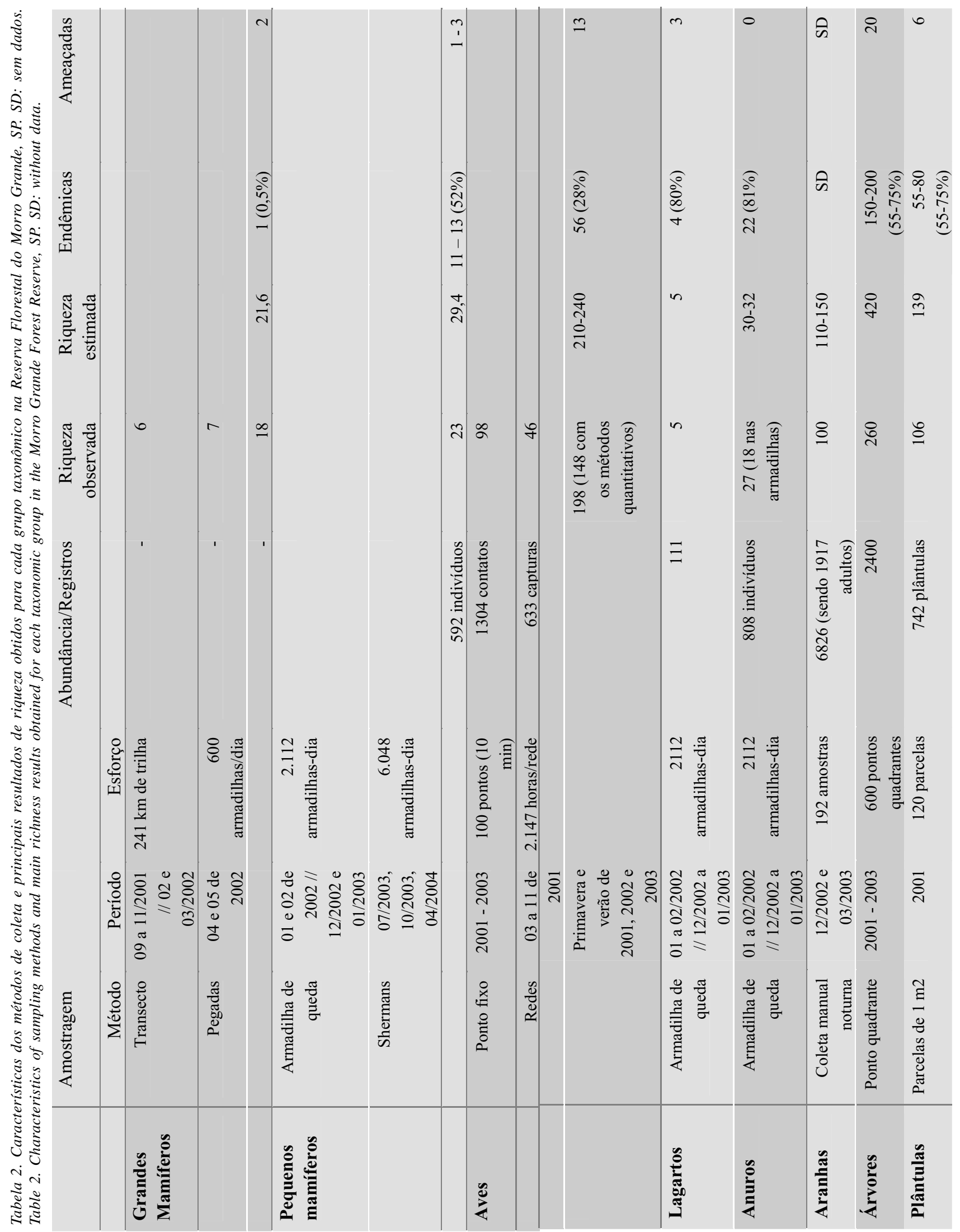


Tabela 3. Diversidades alfa e gama obtidas nas áreas em estádios sucessionais intermediários/avançados (corte raso há cerca de 80-90 anos) e nas florestas maduras (exploração seletiva de madeira, porém sem corte raso) da Reserva Florestal do Morro Grande (Cotia, SP). Em negrito são indicados os valores mais elevados (não foi aplicado nenhum teste estatístico). *: dados de ponto de escuta.

Table 3. Alpha and gamma diversity observed in medium to old secondary forests (80 to 90 years of regeneration) and old-growth forests (or "mature" forests) in the Morro Grande Forest Reserve (Cotia, SP, Brazil). The highest values are in bold (we did not apply any statistical test).

*: point count data.

\begin{tabular}{|c|c|c|c|c|c|c|}
\hline & $\begin{array}{c}\text { Florestas secundárias } \\
\text { intermediárias/avançadas }\end{array}$ & $\begin{array}{r}\text { Riqueza/sítio } \\
\text { (diversidade } \\
\text { alfa) }\end{array}$ & $\begin{array}{r}\text { Riqueza } \\
\text { total } \\
\text { (diversidade } \\
\text { gama) }\end{array}$ & $\begin{array}{r}\text { Florestas } \\
\text { maduras } \\
\text { Áreas } \\
\text { amostradas }\end{array}$ & $\begin{array}{r}\text { Riqueza/sítio } \\
\text { (diversidade } \\
\text { alfa) }\end{array}$ & $\begin{array}{r}\text { Riqueza } \\
\text { total } \\
\text { (diversidade } \\
\text { gama) }\end{array}$ \\
\hline $\begin{array}{l}\text { Árvores } \\
\text { Pequenos }\end{array}$ & 3 & 74 a 93 & 157 & 3 & 103 a 109 & 179 \\
\hline mamíferos & 3 & 11 a 14 & 16 & 3 & 12 a 18 & 22 \\
\hline Aves * & 3 & $55-70$ & 86 & 1 & 75 & 70 \\
\hline Lagartos & 3 & 1 a 2 & 2 & 3 & 1 a 3 & 3 \\
\hline Anuros & 3 & 8 a 10 & 12 & 3 & 9 a 11 & 16 \\
\hline Aranhas & 4 & 41 a 54 & 79 & 4 & 35 a 50 & 76 \\
\hline
\end{tabular}

